\title{
E-Learning in Medical Education: An Experience as a Doctor
}

\author{
Fariha Kauser, Anshoo Agarwal, and Madiha Younas
}

\begin{abstract}
I have created an e learning resource to develop and foster critical thinking skills in dental education. It is an audio podcast created using $\mathrm{Mp3}$ voice recorder. The resource addresses the undergraduate dental students, junior dental faculty. The main aim of introducing this initiative was to facilitate and encourage the dental college to implement the knowledge of critical thinking using deductive reasoning approach. As many patients go unnoticed due to lack of judgemental skills at undergraduate and at faculty level. So, in order to compensate loss and to meet the patients unmet needs, this resource will be of a great help for dental institute and clinics to overcome the problems encountered every day at each outpatient department. I have extensively discussed in article about usability, accessibility, legalities and technical requirement issues related to my resource development. Maintenance, evaluation. Reusability, and stakeholders input also have been explained in depth.
\end{abstract}

Index Terms-E-learning, medical education, doctor, self-evaluation.

\section{INTRODUCTION}

E-learning in medical education is becoming common and popular through useful methods to deliver teaching and learning at under and post graduate level [1]. E resources are best way to communicate in order to convey knowledge and online learning to the students at distant places [2]. Audio podcast, developed is audience centred and focused on interactive element of resource [Appendix 1]. This has been launched keeping in mind the factor of critical thinking skills in dental education that would encourage under graduate dental students to think in spiral fashion with interactive approach. It's an introduction to critical thinking skills development using met cognition analysis in general dentistry.

\section{AIMS AND OBJECTIVES}

Designing an e-learning resource, with particular reference to: target audience; rationale including what needs to be considered and why to choose the modalities used; usability / accessibility / navigability; legal issues; technical support; requirements; relevance; input from stakeholders;

Manuscript received June 26, 2017; revised February 26, 2018.

Fariha Kauser is with University of Dundee, Scotland, UK (e-mail: drfariha06@yahoo.co.uk).

Anshoo Agarwal is with Northern Border University, Kingdom of Saudi Arabia (e-mail: dranshoo3@gmail.com).

Madiha Younas is with Riphah International University, Pakistan (e-mail: madihayounas@live.com). interactivity level; reusability; maintenance; evaluation and review of literature

\section{REVIEW AND DISCUSSIONS}

\section{A. Target Audience and Rationale}

Cultivating critical thinking skills at undergraduate level in multiple disciplines of dentistry remains an unanswered question at most of the occasions [3]. There are various strategies suggested to inculcate the attitudes and behaviours to build up critical thinking skills in medical education [4]. But unfortunately study lacks the acquisition of critical thinking about research in dental education which will produce future practitioners with low self esteem [1]. These skills need emergent attention in multiple disciplines of dentistry where relevant teaching and learning is gained through only by predominated teacher oriented discussions [5]. Findings from a study conducted at Florida underline the need for thoughtful curriculum planning before pre clinical dentistry with periodic appraisal of clinical instructions [5]. Teaching and learning at undergraduate level in institutes is largely dependent on traditional method which includes bed side teaching and dental chair instruction. But today living in the era of medical education, critical thinking skills are necessary and one of the main stream to foster independent learning to produce future dentists [6]. Another study presented some of changes mandatory to inculcate these skills in dental learning environment [1]. The whole strategy for teaching dentistry in multiple disciplines need to be addressed to bring such an effective change to save the society and mankind [3], Henceforth development of strategic curriculum planning to promote critical thinking skills is an immediate step to produce future dentists with logical understanding to overcome issues in dental society [2]. The purpose and rationale of the resource is to engage all stakeholders to facilitate and educate lifelong learning and to provide evidence based dental education to all the students at undergraduate level before preclinical dentistry. Clinical dentistry is a branch of dentistry which prepares dental undergraduates to deal with real life situations encountered in a clinical learning environment [7]. This discipline of dentistry is considered as a second line education drug in dental community. The main idea for creation of resource named "critical thinking skills in dental education"' is to build and construct sense of logical and metacognition analysis in dental clinics where undergraduates and teaching faculty faces various patients of complex medical history. Operative dentistry is where broken or damaged tooth structures are restored with several dental materials to treat 
the dental diseases [8]. Thoughtful curriculum planning, problem based learning, advanced faculty development, assessment and introduction to critical thinking are fundamental steps to be kept under consideration in today's dental education world [2]. The concept of revitalization of critical thinking analysis and matters related to its implication in dental education are urgent initiatives in twenty first century [8]. Measurement of those skills requires quality enhanced approach which includes surveys, assessment, feedback and e-moderated activities for evaluation.

\section{B. Usability, Accessibility and Navigation}

There are four steps of usability concept while creating and launching e resource of critical thinking skills in dental education. These concepts are termed as academic, general, technical and context specific [9]. Usability and accessibility related to context requires the content and structure to be relevant for future dental practitioners and undergraduate students in multiple disciplines of dentistry. Reliability and generality of the resource have to be recognized by the international recognized body of American dental students and education society. The concept of general usability includes transparent navigation and accessibility of the resource.

\section{Legalities}

Mostly, Aspects of any resource demands no copyright infringement of any sort [7]. The idea of copyright safeguards the data and content of the resource. The sustainability of the copyright belong to the person who created the resource or to the institution for up to 70 years from the death of the author. The patient's right to acquire quality enhanced dental care under the WHO Health Guidelines presented in ministry of Health (UAE) manual.

\section{Technical Support Requirements}

The resource is accessible on windows $\mathrm{Xp}$, mac and windows vista platform to watch or listen the audio. E moderation for this online asynchronous discussion must be directly supervised by logging in to the instructor driven module of e learning. Tracking of records and frequency of usage of the resource should be obvious on webpage if required to monitor the audience interaction. All other technical support should be made available to all the undergraduate students and faculty in case of resources becomes faulty or if confronted with resource usability and notability.

\section{E. Input from Stakeholders}

There always has to be inclusion of possible stake holder for launching e resource. Stake holders for this initiative are undergraduate dental students from year 4 and year 5, junior instructor faculty, patients from College of dental sciences, and ministry of health UAE. All stakeholders may not get engaged with the resource directly but their contribution may aid the process of needs analysis. Surveys and feedback are essential guide in assessment of the Resource at College of dentistry to promote critical thinking skills using deductive reasoning approach. Topic, content and teaching methods have to be aligned with the guidelines of the Americans dental students' society and ministry of health UAE. To improve the efficacy of resource, continuous evaluation and needs analysis through mixed methods have to be initiated for effectiveness and sustainability. External assessment of the resource and validity aids the process of construction of knowledge and collaboration with other bodies [6]. Faculty development program must be introduced to bring awareness about critical analysis skills and to generate the metacognition analysis abilities. Resource must be updated quarterly and annually according to comments, suggestions and feedback from all stake holders.

\section{F. Interactivity}

Interactive audio in a teaching and learning environment using computer system allows proactive and interactive participation of learners. Interactivity can be judged by number of participants and duration of review by each learner [9]. Audio cassettes and files used in an e learning environment promotes self-directed learning [10]. One of the biggest advantage of using audio podcast for the purpose of conveying content knowledge that aids in building up critical thinking skills in one self [10]. Alternatively pitfall of using the video is lack of creating or encouraging to think critically while reviewing the video podcast [10]. Participants must be able to listen the resource as many as they wish to and make notes or use the transcript. The aim is to focus on individualized learning [6]. Discussion boards allow peer to peer inter active talk session to facilitate learning between groups [11].

\section{G. Reusability and Maintenance}

Reusability refers to the factors that are considered as technical format, textual dependency, and technical dependency [12]. But Video lacks the ability to generate critical thinking skills in one self [7]. Vertical reusability determines the effectiveness and distribution of resource over other educational organizations whereas horizontal reusability refers to the extent that how widely it can be used over multiple areas. This resource has been produced with subject specification to introduce critical thinking skills at undergraduate level in dental education. E resource maintenance is a complex phenomenon that includes basic text, graphic images (if any) translation of the written material, copy of manuscript, body of localization and familiarization [13]. Any e learning resource maintenance must prevent excessive time duration, fatigue and most importantly cost that can be significantly analyzed through appropriate design and development of the resource.

\section{H. Evaluation}

Evaluation is a systematic method for collection, analysis, and interpretation of information about any aspect of resource design, its implementation and utility of educational programs to measure the teaching [14]. Evaluation consists of mainly four levels which are planning and implementation of action, teaching and learning activity, collection and measurement of evaluation data on activity, and analysis of reflection records [15]. There are various proposed model available for evaluation of the resource but commonly used RUFDATA as a template to evaluate the resource [16]. The main reason behind evaluation is to find any area of improvement that can be beneficial to learners. Aim of the 
resource must be aligned with clinical requirement of all multiple disciplines of dental education at institutional level. Likert scale (Appendix 2) aims to achieve qualitative data as part of evaluation cycle. The information gathered must be accessible to the author and e learning data must include learning environment, contextual content, technology, individual learning experience and pedagogic impact [17]. These variables must be assessed by administering a questionnaire to each participant at the end of the resource presentation. Three wide levels highlighted by Anderson in 2001 are objective measures of content and interaction quality.

\section{CONCLUSION}

There is an instantaneous need to introduce such e learning resources at undergraduate level for sake of delivering high quality dental treatment. Some e moderated teams have shown great impact for evaluating such resources. But scarcity of these resources, makes hard to assess value of learning on long term basis because main objective of such resources is to maintain patient's health, safety and provide the highest quality dental care to the patients and society [18]. It is slightly easier said than done to evaluate such resources, but there is a critical mind behind every recovered and optimistic patient in dental clinic.

\section{APPENDIX}

\section{Appendix 1:}

\section{A. Activity for Learners}

Critical thinking is a natural way of getting into a thought but using an uninformed and biased approach [19]. In order for an undergraduate student to become a critical thinker, there are four learning objectives and those are explained in the appendix previously.

Analysis

Inferences

Interpretation

Deductive reasoning

Students will listen to audio podcast (clinically oriented case based scenario) to assess their level of critical thinking. All students will be divided into five groups of ten. The duration for the whole workshop is two hours and thirty minutes. All the audience will listen to audio podcast and have a small session among group members for brain storming [20]. We will use blended learning approach here as you expect to find all types of learners such as aural, kinaesthetic, read write, interpersonal, visual and intrapersonal [21]. Everyone will have the freedom to choose alternative words for critical thinking analysis [22]. All the leaflets containing case based scenarios will be distributed among all undergraduates with some guidelines and suggested reading materials. They will be provided with some e journals links, you tube videos, animated material and book readings [23]. The duration including tea break would consists of one hour and 45 minutes. After the brain storming session is over, and each group have jot down the points, then one of the group members will be asked to present the case presentation and duration will remain five minutes including peer review and discussion for each group. Once all five groups have accomplished their presentation and received peer feedback, 15 minutes will be served to assess and measure the critical thinking skills at undergraduate level by administration of a quiz containing MCQs.

\section{Appendix 2:}

\section{B. Evaluation Tool to Measure Overall Impact of E-learning Resource}

This will be administered to all the undergraduate staff and students in dental teaching institute to evaluate their understanding.

( $\mathrm{SA}=$ Strongly agree, $\mathrm{A}=$ agree, $\mathrm{SD}=$ Strongly disagree, $\mathrm{D}=$ Disagree)

1) This e learning resource is useful to implement in clinically oriented dental scenarios to develop critical thinking skills? SA A SD D NEUTRAL

2) This is beneficial tool for undergraduate dental students and staff in clinically oriented case based discussions?

\section{SA A SD D NEUTRAL}

3) This will be helpful tool if dental school wide programme has been conducted on annual basis?

\section{SA A SD D NEUTRAL}

4) This e learning resource will enhance teaching and learning in a critical manner?

\section{SA A SD D NEUTRAL}

5) Ministry of education UAE will grant funds in future for its implementation at post graduate level?

\section{SA A SD D NEUTRAL}

Information obtained from this above feedback will help us to improve and implement resource in future at a national level in United Arab Emirates in order to get collaboration with institutes at a post graduate level.

\section{REFERENCES}

[1] J. G. Ruiz et al., "The impact of e-learning in medical education," Academic Medicine, vol. 81, no. 3, pp. 207-212, 2006.

[2] G. Salmon, E-Moderating: The Key to Teaching and Learning Online, Psychology Press, 2004.

[3] L. S. Behar-Horenstein et al., "Cultivating critical thinking in the clinical learning environment," Journal of Dental Education, vol. 64, no. 8, pp. 610-615, 2000 .

[4] A. G. Fincham and C. F. Shuler, "The changing face of dental education: The impact of PBL," Journal of Dental Education, vol. 65, no. 5 , pp. $406-421,2001$.

[5] A. Muir et al., "The pyramid of usability: A framework for quality course websites," in Proc. of EDEN 12th Annual Conference of the European Distance Education Network, The Quality Dialogue: Integrating Quality Cultures in Flexible, Distance and eLearning, Rhodes, Greece, 15-18, June 2003, 188-194. 2003.

[6] J. E. Stice, "Using Kolb's learning cycle to improve student learning," Engineering Education, vol. 77, no. 5, pp. 291-96, 1987.

[7] JISC. (2013). Legal guidance for ICT use in education, research and external engagement. [Online]. Available: http://www.jisclegal.ac.uk/ManageContent/ViewDetail/ID/129/Copyr ight-Law-for-e-Learning

[8] D. C. Johnsen et al., "A model for critical thinking measurement of dental student performance," Journal of Dental Education, vol. 73, no. 2, pp. 177-183, 2009.

[9] JISC. (2009). Supporting personalized \& collaborative e-learning in Foundation degrees. [Online]. Available: http://www.jisc.ac.uk/publications/reports/2009/spacefdfinalreport.as px\#downloads

[10] J. W. Fisher et al., "Learning joint statistical models for audio-visual fusion and segregation," In NIPS, pp. 772-778, 2000.

[11] R. M. Harden, "Ten questions to ask when planning a course curriculum," ASME Medical Education Booklet No. 20, Medical Education, vol. 20, p. 356, 1986. 
[12] D. Zhang et al., "Instructional video in e-learning: Assessing the impact of interactive video on learning effectiveness," Information and Management, vol. 43, no. 1, pp. 15-27, 2006.

[13] K. B. Williams et al., "Predictive validity of critical thinking skills and disposition for the national board dental hygiene examination: A preliminary investigation," Journal of Dental Education, vol. 70, no. 5 , pp. 536-544, 2006.

[14] D. P. DePaola, "The revitalization of US dental education," Journal of Dental Education, vol. 72, no. 2, pp. 28-42, 2008.

[15] E. Mamary and P. Charles, "Promoting self-directed learning for continuing medical education," Medical Teacher, vol. 25, no. 2, pp. 188-190, 2003.

[16] J. Phillips and Z. L. Berge, "Second life for dental education," Journal of Dental Education, vol. 73, no. 11, pp. 1260-1264, 2009.

[17] C. O'Brien. (2005). Elearning maintainance strategies: Why you need one. Presented in ASTD International Conference. [Online]. Available: www.elearningguild.com/showfile.cfm?id=2117

[18] M. Pyle et al., "The case for change in dental education," Journal of Dental Education, vol. 70, no. 9, pp. 921-924, 2006

[19] S. C. Bayne et al., "Sturdevant's art and science of operative," 2006.

[20] M. Saunders, "Planning an evaluation with RUFDATA: Theorising a practical approach to evaluation planning," Evaluation, vol. 6, no. 7, 2000.

[21] A. R. Seitz et al., "Sound facilitates visual learning," Current Biology, vol. 16, no. 14, pp. 1422-1427, 2006.

[22] J. E. Stice, "Using Kolb's learning cycle to improve student learning," Engineering Education, vol. 77, no. 5, pp. 291-96, 1987.
[23] R. Wutoh et al., "ELearning: A review of Internet-based continuing medical education," Journal of Continuing Education in the Health Professions, vol. 24, no. 1, pp. 20-30, 2004.

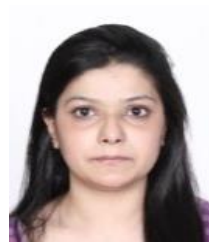

Fariha Kauser got the B.D.S. (bachelor in dental surgery) from the Ras al Khaimah, Medical university, UAE; the diploma in medical education, University of Dundee, Scotland.

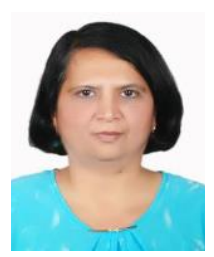

Anshoo Agarwal got the M.B.B.S. (bachelor of medicine $\&$ bachelor of surgery) from the King George Medical College Lucknow, India; the MD pathology (doctor in medicine) from Ch Charan Singh University, India.

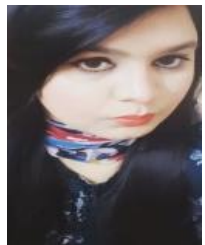

Madiha Younas got the masters in cardiopulmonary Physical Therapy from Riphah International University, Pakistan; the DPT (doctor of physical therapy) from Riphah college of Rehabilitation Sciences Rawalpindi, Pakistan. 